\title{
METALLURGY DIVISION
}

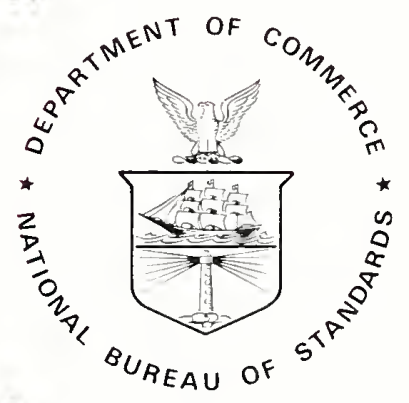

Letter Circular 1125

August 1980

Center for

Materials Science

The National

Measurement Laboratory

National Bureau

of Standards

U.S. DEPARTMENT

OF COMMERCE 
8

$\infty$ 


\section{Metallurgy Division at NBS}

The Metallurgy Division of the Center for Materials Science at NBS has long been recognized for the high quality of its research and contributions toward the solution of national metallurgical problems. The purpose of this booklet is to provide a brief review of the Division's past and present research activities and to indicate areas of interest for future investigations.

Because this booklet has purposely been kept brief, no pretense of including all of the technical highlights of the Division's activities is made. It is hoped, however, that the reader will find the cited items both interesting and informative.

Dr. Robert Mehrabian

Chief, Metallurgy Division 1980 


\section{Metallurgy Division - To Communicate}

- Dr. Robert Mehrabian

Chief, Metallurgy Division

Matls. Bldg., Room B266

Phone: (301) 921-2811

- Dr. Anna C. Fraker

Deputy Chief, Metallurgy Division

Matls. BIdg., Room B266

Phone: (301) 921-2812

Group Leaders

- Dr. J.R. Manning

Matls. Bldg., Room A153

Phone: (301) 921-3354

- Dr. M. Kuriyama Matls. Bldg., Room A161

Phone: (301) 921-2986

- Dr. A.W. Ruff

Matls. Bldg., Room B114

Phone: (301) 921-2966

National Bureau of Standards

Washington, DC 20234

Larry Ketron, Coordinator 
NBS Metallurgy

Division Chiefs

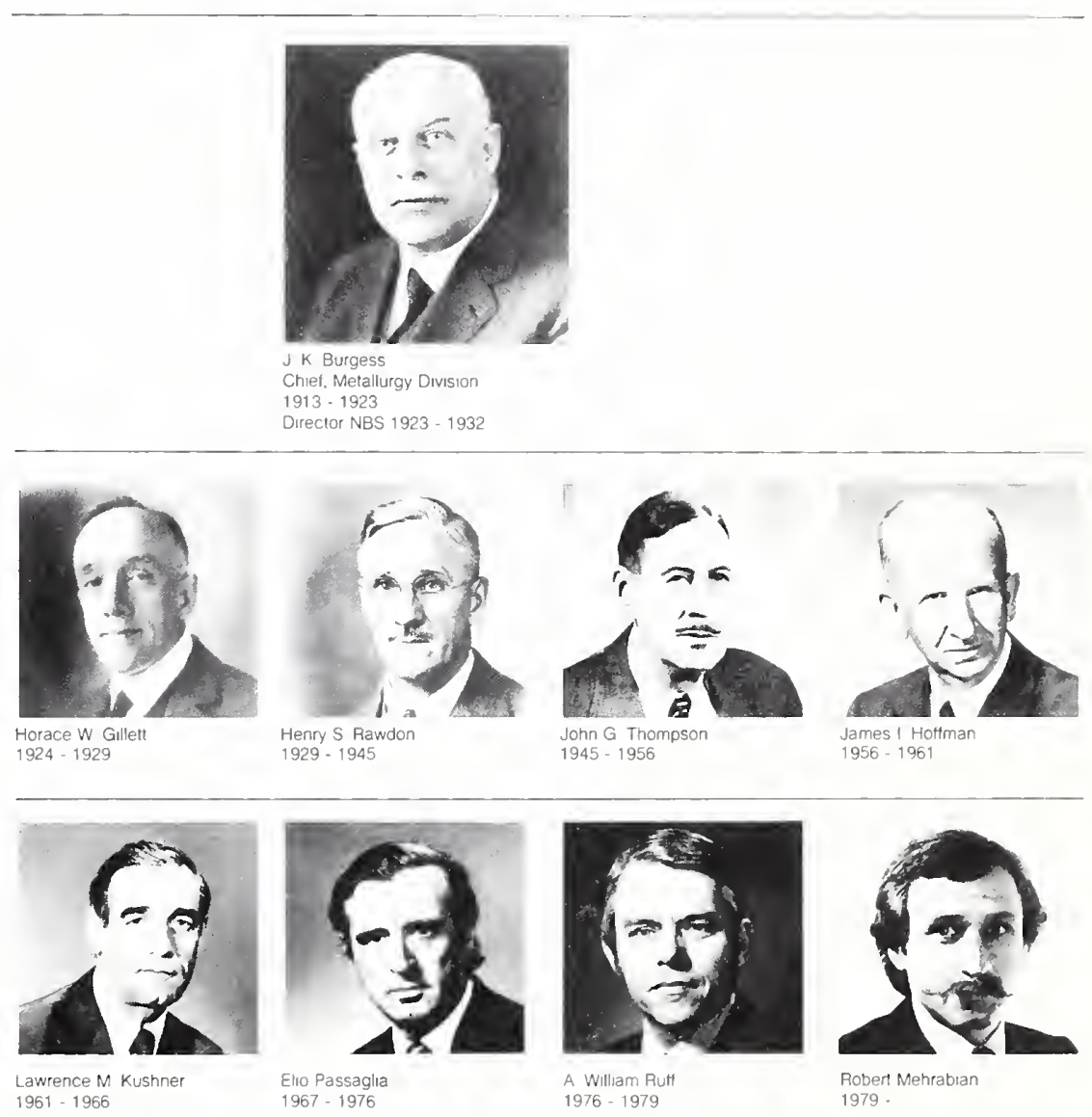




\section{History}

Metallurgical research has formed a significant part of the NBS activities from virtually the very day the Bureau was established in 1901. The early work of the metallurgists addressed problems such as the determination of the melting points of metals, development of techniques for establishing phase diagrams, testing of transformer steels and investigations of alloys and structures used in the railroad industry.

The Metallurgy Division was formally established in 1913 under the leadership of the man who was to become the second Director of NBS, G.K. Burgess. It was the first Division formed at NBS devoted solely to the study of materials, and has remained in operation since that time. Over the years the work of the Division has been associated with internationally recognized leaders such as George Burgess, Paul Merica, Alexander Krynitsky, John Thompson, James Hoffman, Thomas Digges, Samuel Rosenberg and Melvin Romanoff. These are but a few of those in the past that guided and carried out the metallurgical research that has contributed to the solution of a range of national problems.

During the period encompassing World War I and to the end of the twenties, the Metallurgy Division's research efforts broadened extensively. It involved areas such as the development of cathodic protection for pipelines and the chemical, physical, and structural properties of alloys used for shells, guns, armor plate, high speed tools and aircraft. Out of these efforts a number of significant technical advances were made. The work of Merica, Waltenberg and Scott in 1919 produced the first explanation of the phenomena of age hardening of metals.

Following the war, pioneer work was carried out by French and Tucker on the creep of metals at elevated temperatures. Work was initiated in 1927 to determine the wear of metals and methods for reducing wear. An experimental foundry was formed and standard testing methods for the evaluation of molding and core sands were developed. In addition to gasfired and electric furnaces, an experimental cupola was designed and constructed for the production of cast iron. The pouring characteristics of cast iron were investigated. This led to the development of the now well known fluidity spiral by Saeger and Krynitsky in 1931. Other work involved determination of the shrinkage of various metals and alloys during solidification. 
Through the 1930's cooperative investigations were undertaken with industry and various national organizations including the Non-Ferrous Ingot Metals Institute, American Society of Mechanical Engineers, The Engineering Foundation, The American Society for Testing Materials, The Copper and Research Association, The American Institute of Metallurgical Engineers and others. Results of these studies are too numerous to mention here, but ranged from the determination of fundamental physical properties of metals to microstructural characteristics of welded steels.

World War II brought national concern for the conservation of strategic raw materials such as chrominum, tungsten and molybdenum used in steels. Investigations were undertaken in the Metallurgy Division by researchers such as S.J. Rosenberg, T.G. Digges and A. Brenner to address these problems by examining the properties of "lean alloy" steels and to develop new coatings and processes. An important contribution to the war effort was made by Dr. M.L. Williams in his study of the breaking-up of Liberty Ships.

In 1953 the "Kelly Committee" submitted their report to the Secretary of Commerce on the functions and operations of the National Bureau of Standards. Following the recommendations of this committee, the Metallurgy Division entered a period of expansion and gradual shift of emphasis to fundamental research.

By 1957, a new section entitled Metal Physics was added to the Division in recognition of the changed state of metallurgy as a science. New research projects were started that were concerned with diffusion, crystal growth, structural defects in metals, and the electronic properties of metals. Studies of the formation of oxide films on clean single crystals were initiated and the Metallurgy Division pioneered the application of ellipsometry to the study of corrosion processes.

In 1963 the Metallurgy Division underwent its first major reorganization. Even the everyday vocabulary changed as projects emerged that were concerned with dislocation movement, point defects, nuclear magnetic resonance, electronic properties below 4 degrees Kelvin, Kossel Lines and the $x$-ray topography of single crystals. During this period, the Metallurgy Division became a leader in the development of new methods for measuring properties of metals important to meeting our national needs in energy, environment and industrial technology. 
During the late 1960's and the early 1970's significant contributions were made in areas such as interface stability during alloy solidification, the quantum theory of $x$-ray diffraction for crystal characterization, and diffusion kinetics in alloys. Work on the electronic density of states in metals and alloys was directed toward alloy stability and chemical bonding as well as catalysis and fuel cell electrodes. Data was published on hyperfine fields, and applied to problems in corrosion, standards for ferrite content of welds, and nondestructive testing. Other work involved theoretical and experimental advances in the application of electron probe analysis, and the quantitative determination of stacking fault energy in alloys using electron microscopy and $x$-ray diffraction techniques and pioneer work in field emission microscopy.

In a recent reorganization of NBS in April 1978 the Corrosion Section and some of the personnel in the Mechanical Properties Section were transferred out of the Metallurgy Division and combined with other groups to form two new Divisions in the Center for Materials Science. However, new initiatives in Wear and Synchrotron Radiation and renewed emphasis on research in the fields of Chemical and Process Metallurgy and NDE have resulted in the addition of twelve new scientific personnel in the past year and a broad range of new research activities in the Metallurgy Division.

The mission of the present Metallurgy Division and a summary of its activities are described in the subsequent sections. 


\section{Metallurgy Division}

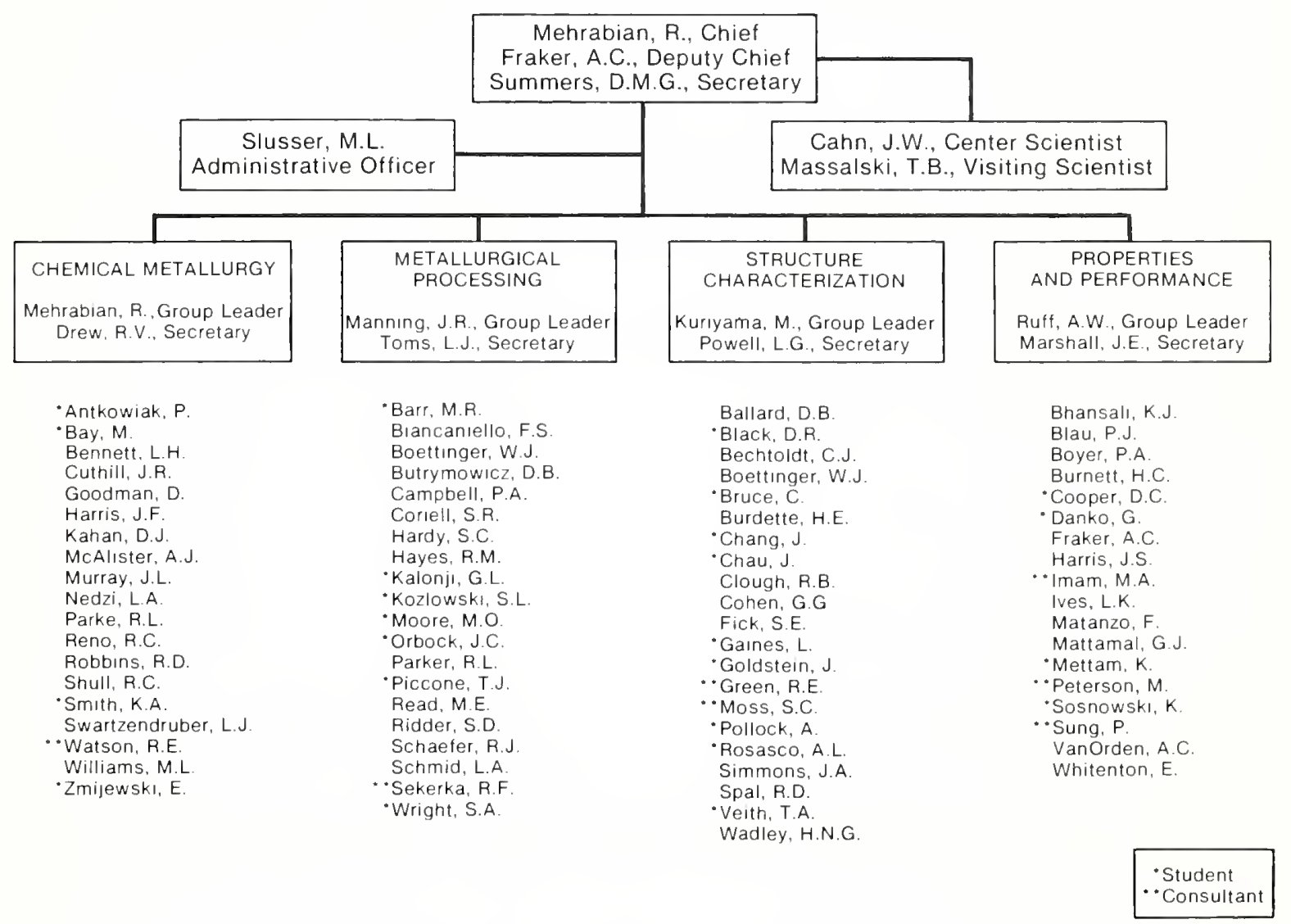




\section{Mission and Current Activities of the Metallurgy Division}

The mission of the Metallurgy Division is to provide data, measurement methods, standards and reference materials, concepts and information on the fundamental aspects of processing, structure, physical properties and performance of metals and alloys to industry, government agencies and scientific organizations.

The program of the Division involves studies of metals and alloys in order to foster their safe, efficient, and economical utilization to meet our national needs within the larger framework of the materials cycle. Competences are developed and maintained in the general areas of chemical metallurgy with special emphasis on phase diagrams and phase stability; process metallurgy; quantitative microstructural characterization including nondestructive evaluation; properties including friction, wear, and the application of metals as synthetic orthopedic implants. The Division also makes a significant contribution as a national resource of metallurgical information through its Diffusion Data Center and Alloy Data Center. It provides consultation and assistance to other government agencies and standards organizations in the development of necessary test methods and standards. The programs of the Metallurgy Division are designed to help us meet our future national needs for materials, which will depend in large measure on our response to forces which are now well recognized. Some of these are classical laws of supply and demand; others include such national problems as energy, environment, productivity, and such international problems as materials availability from third world nations.

For example, our Division, in addition to being involved in theoretical and experimental studies of phase stability, has a joint effort with the American Society for Metals to provide critically evaluated phase diagrams to the metallurgical community. Advancement in the understanding of phase diagrams and the development of predictive models for phase stability are essential in the development of new alloys for our future needs. These could include stronger and lighter alloys for the transportation industry to improve energy cost, new alloys specifically designed to exploit the beneficial effects of innovative new processes such as those referred to as rapid solidification processes, and alloys which would permit substitution of scarce or unavailable elemental constituents. 
The detailed programmatic content of the Division that follows is described in the four task areas:

- Chemical Metallurgy

- Metallurgical Processing

- Structure Characterization

- Properties and Performance

The technical activities under the various tasks are closely interrelated and address the overall mission of the Division to meet our present and future societal needs for metals. The central purpose of these scientific activities is to probe the relationships among processing conditions, the internal structure of metals, and their properties and performance. The resulting knowledge can be used to efficiently produce, shape, and otherwise process metals to control their properties and achieve the desired reliable and durable performance in the finished product.

The figure on the opposite page illustrates the interaction of the various efforts.

The results of our metallurgical research are communicated to the scientific community through technical publications, lectures, active participation of Division members on various national and international committees, personal contacts, and the organization and sponsorship of conferences and meetings on various subjects such as acoustic emission, synthetic implants, alloy phase formation, solidification, wear and mechanical failure prevention. 
The Metallurgy Division's activities probe four areas of research. Each technical Group is organized to carry out its particular mission and goals. The programs of the four technical groups are, however, interrelated and cooperative interaction forms an active bond of mutual interest and dependence.

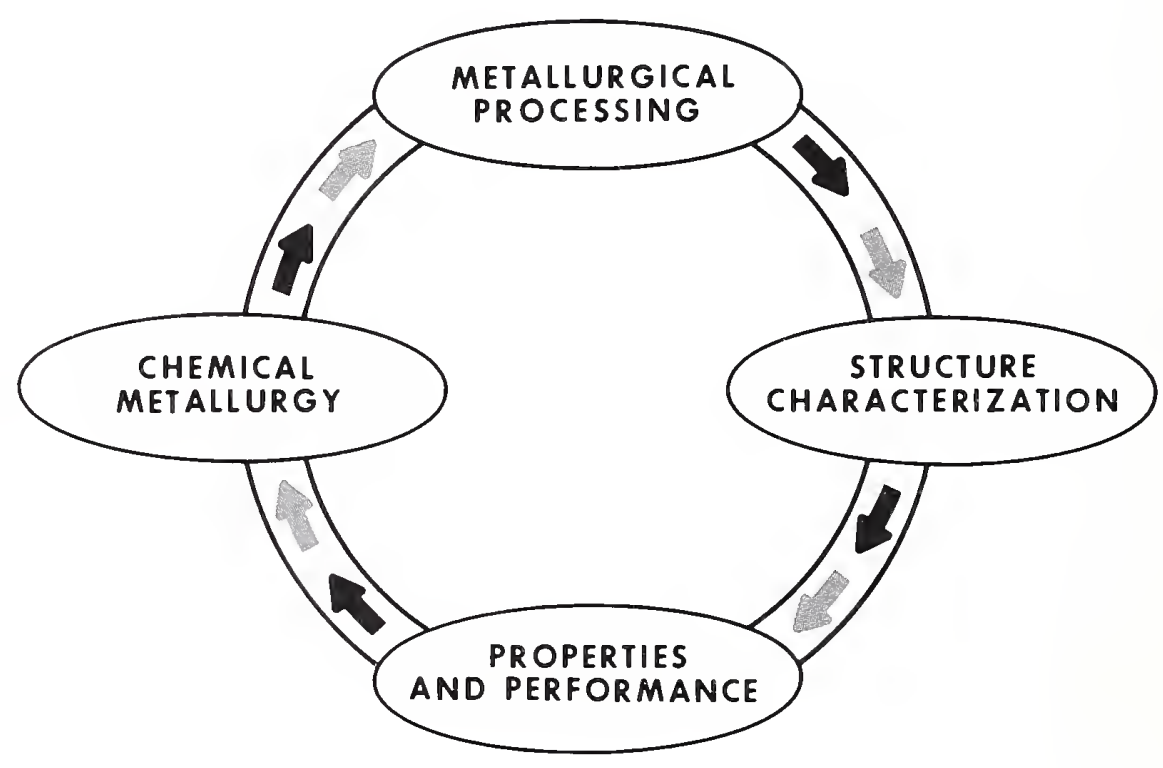

\section{METALLURGY DIVISION'S ARENA OF ACTIVITIES}


Critical data compilations are being developed and delivered to users concerned with alloy properties, diffusion, and phase diagram information. Standard reference materials are being produced for electron microscope calibration, electron microprobe analysis, and electrical conductivity. Contributions are made to NBS programs in nondestructive evaluation, recycled oil and materials, and artificial implants.

Productive interactions with other groups at NBS exist in areas such as surface analysis, wear, microstructural characterization, acoustic emis. sion and phase diagrams. Computer graphics methods incorporating phase diagram predictive techniques and thermodynamic data are being developed in collaboration with the Applied Mathematics Division of the National Engineering Laboratory.

The available competences in the Division have recently been strengthened and expanded by:

- The appointment of a process metallurgist as the new Division Chief in 1979.

- A successful budget initiative in the area of metallic wear.

- A new competence initiative within the National Bureau of Standards to develop research programs at the Synchrotron Light Source at Brookhaven National Laboratory with the main materials expertise to reside within the Metallurgy Division.

- The addition of twelve new scientific staff members in the past twelve months.

- The development of new programs aimed at promoting technical innovation and improving our national productivity in the field of metals processing. 


\section{Chemical Metallurgy}

The interplay between thermodynamic predictive models and the formation and stability of alloy phases is the central theme of this group's activities. This theme is developed in data, theory and experiment. Conventional and new experimental techniques are combined with theoretical models in the determination and prediction of phase diagrams. Special emphasis is placed on the development of on-line computer graphic systems. In addition to its fundamental scientific interest, advancement in the understanding of phase diagrams is essential to permit greater flexibility in development of new alloys for improved performance, ease of processing, reduced cost and energy use, as well as in providing substitutes for scarce elemental additions. A joint effort with the American Society for Metals is underway to develop and disseminate critically evaluated alloy phase diagrams. A semi-annual Bulletin of Alloy Phase Diagrams is also published under this program.

The Alloy Data Center of the National Bureau of Standards is located in the Chemical Metallurgy Group. This Center is a national metallurgical resource, providing a central source of extensive evaluated data on alloy phase diagrams and the physical properties of alloys to a large user community in government, industry and universities.

\section{Current Research Projects in Chemical Metallurgy}

- Experimental Determination of Ternary Phase Diagrams in Titanium Alloys

- Development of Predictive Models for Alloy Phase and Structural Stability Based on Physical Parameters

- Development of Thermodynamic Computer Models for Prediction of Phase Diagrams

- Development of Interactive Computer Graphics System for Phase Diagrams

- Publication of the Bulletin of Alloy Phase Diagrams in Cooperation with ASM 
- Measurement of Thermodynamic Properties of Binary Alloys

- Formation and Stability of Amorphous Metallic Phases

- Electrocatalytic Characterization of Pt-W-C Alloys and the Formation of Surface Phases

- Quantitative Identification of Phases by Mossbauer Techniques

- Study of Interstitial Compounds/Transition Metal Carbides, Nitrides and Borides for Fuel Cell Electrodes

- Compilation, Critical Evaluation and Publication of Alloy Phase Diagrams

- Prediction of Enthalpy of Formation of Transition Metal Alloys 


\section{Metallurgical Processing}

Metals processing research plays a central role in the Division's activities and is the controlling factor in the interplay between the other three groups. The properties of alloys depend on their compositions and microstructures which are dictated by their processing history. Thus, the effective performance of components in societal use depends strongly on solidification and solid state transformation processes, diffusion and other kinetic changes that alloys undergo during production and shape forming operations. The central objective of this group is to develop data, measurement techniques, theory and predictive models relating variables during metallurgical processing to microstructures, hence properties and performance of alloys.

In addition, the Diffusion in Metals Data Center of the National Bureau of Standards is located in this group. This Center is a national metallurgical resource that provides a central source of extensive evaluated data on diffusion to the technical community at large.

\section{Current Research Projects in Metallurgical Processing}

- Compilation, Evaluation, and Dissimination of Diffusion Data

- Mathematical and Physical Modelling of Macrosegregation in Castings and Ingots

- Effect of Thermomechanical Treatment on Structure of Aluminum Alloys

- Microsegregation and Stability at the Solidification Interface

- Surface Tensions and Their Variations with Temperature and Impurities

- Development of Heat Flow Models for Rapid Solidification

- Diffusion Induced Grain Boundary Migration 
- Relationship Between Heat Flow and Microstructure in Surface Melting and Welding

- Development of Ultrasonic Techniques for Liquid-Solid Interface Velocity Measurements

- Metastable Reaction Sequences in Multicomponent Systems

- Formation of Amorphous Structure During Rapid Solidification

- Electron Beam Processing of Metals

- Effect of High Rate Solidification on Microstructure

- Development of Theory of Diffusion Defect Fluxes

- Solutal Convection During Directional Solidification

- Transparent Modelling of Solidification Processes 


\section{Structure Characterization}

Innovative processing techniques are being developed to produce significant new microstructures and structure/property relationships. Coupled with increased industrial emphasis on quality control and automation, these require a range of microstructural characterization and nondestructive evaluation methods. The objectives of this group are to address this challenge by the development of measurement methods including non-destructive techniques and standards for the advanced quantitative characterization of metallurgical microstructures. Methodologies include $x$-ray, optical and electron microscopy, eddy current, magnetic particles, positron annihilation, acoustic emission and ultrasonic methods.

\section{Current Research Projects in Structure Characterization}

- Development of Synchrotron Radiation Beam Lines for Metal Science at Brookhaven

- Development of Real Time Radiography with X-ray Magnifiers for Quality Control of Alloys

- Development of Positron Annihilation Doppler-Broadening for Microstructure Characterization

- X-ray Small Angle Scattering and Energy Dispersive Diffractometry Analysis of Metallic Glasses

- Correlation of Defect Source Mechanisms, Alloy Microstructure and Acoustic Emission Signatures

- Multichannel Quantitative Acoustic Emission (AE) Waveform Analysis

- Development of Real Time Topography for Phase-Transformations, and Microstructure Characterization

- X-ray Chemical Profile Analysis for Alloy Systems 
- Development of Reproducible Microcrack and Phase Transformation AE Sources in Alloy Plates

- Advanced Signal Processing and Pattern Recognition Algorithms to Reconstruct AE Sources in Complex Systems

- Development of EXAFS, SEXAFS and Fluorescence EXAFS Techniques at Interfaces of Oxide and Corrosive Films in Metals

- Theoretical Studies of Elastic Wave Propagation and Scattering for AE and UItrasonic Metals Characterization

- Residual Stress Evaluation in the Interior of Shaped Components by Energy Dispersive Diffractometry Using a High Energy X-ray Source

- Development of Quantitative Models for Magnetic Particle NDE

- Correlation of Ultrasonic and Eddy Current Indicators with Microstructure and Mechanical Properties in Aluminum Alloys

- Development of Eddy Current Calibration Standard Reference Materials 
Properties and Performance of Metals

The adequate performance of metals in service depends on their properties and structure as well as design and environmental considerations. The research activities of this group are directed toward the provision of data and understanding in two areas - the wear performance of metals, and the fatigue and corrosion behavior of metals used as synthetic implants in humans. The performance of metals in these areas depends critically on such parameters as phase type and stability, microstructure and alloy composition. Significant differences in wear performance of metals can result from controllable variations in alloy composition and structure. This group is actively developing new measurement and test methods to improve the ability to accurately determine relevant metal properties. Studies are being carried out to determine the controlling parameters and important basic mechanisms in wear and in implant alloy corrosion and fatigue.

Several of the activities in this group also involve the NBS Office of Standard Reference Materials and the American Society of Testing and Materials Committees on Erosion and Wear and on Medical and Surgical Materials and Devices. In this way, coordinated effective programs to develop standard methods of measurement and testing are carried forward involving many other laboratories in the university and private sectors.

\section{Current Research Projects in Properties and Performance of Metals}

- Determination of the Role of Plastic Deformation in Metal Wear Processes

- Measurement of Abrasive Wear Rates in Metals and Metal Coatings

- Investigation of Galling and Scuffing Wear Processes in Metals and the Role of Stacking Fault Energy

- Development of Laboratory Methods to Measure Fretting Wear Behavior of Implant Alloys

- Development of Experimental Methods for Studying Low Cycle Fatigue Effects in Metal Wear 
- Determination of Wear Mechanisms Involved with Rapidly Solidified Metal Layers

- Measurement of Solid Particle Erosion Rates in Metals Including the Effect of Particle Flux and Microstructure

- Development of Laboratory Methods to Evaluate the Wear Characteristics of Rerefined Engine Oils

- Investigation of Corrosion-Fatigue Processes in Implant Alloys Including the Effect of Microstructure

- Development of Reference Materials for Standardizing Abrasive Wear and Erosive Wear Measurements

- Collaboration with ASTM-G2 Committee on the Development of Standard Wear and Erosion Test Methods

- Investigation of the Effect of Antimony-Sulfur Compounds on the Wear of Steel and Titanium

- Measurement of Repassivation in Implant Alloy Corrosion Processes 


\section{Other Activities}

The Metallurgy Division's programs also include significant direct contributions to industry, through the NBS Research Associate Program, conferences, workshops, organization of seminars, technical publications, and personal contact. Extensive interaction with universities exists through the Cooperative Education Program, NBS Postdoctoral Program and faculty guest workers. Considerable interaction also exists with other government agencies, standards organizations, and the technical community at large. For example, the Division performs research for the following government agencies:

- National Aeronautics and Space Administration

- Office of Naval Research

- Defense Advanced Research Project Agency

- Department of Energy

- Naval Ship Research and Development Center

- U.S. Army Materials and Mechanics Research Center

- U.S. Army Mobility Equipment Research and Development Command

The personnel in the Division serve on numerous ASTM Committees, including Chairman of the B.6 Committee and Past Chairman of Committee E-42, Vice Chairman of Committee G-2, and chairman of several subcom. mittees. The technical staff have organized and chaired two international conferences on Rapid Solidification Processing, an international conference on Implant Retrieval: Material and Biological Analysis, and each year organizes and conducts two conferences on the Prevention of Mechanical Failures, and is organizing the 1981 International Conference on Wear. The Metallurgy Division's staff serve on over sixty other national professional and technical committees. 
0

$\infty$

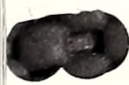


$\infty$

80

6 